\title{
¿Responsabilidad estricta por el hecho ajeno de una clínica? (Corte Suprema)
}

\author{
Comentario de Juan Vio Vargas*
}

Santiago, diecinueve de junio de dos mil catorce.

$[\ldots]$

Y teniendo además y en su lugar presente:

$1^{\circ}$ ) Que los argumentos centrales de la sentencia del primer del grado -más allá de sus problemas estructurales y sus numerosos errores gramaticales, que se repetían en segunda instancia- son los eficientes y adecuados para resolver la contienda suscitada en estos autos, más allá de que deban ser mejorados y profundizados.

En efecto, y más allá del vehículo procesal escogido para potenciar su pretensión, resulta evidente del decurso del proceso que la parte demandante pretende -para sí y sus hijas menores- el resarcimiento del daño ocasionado por la muerte de su cónyuge, ocasionada con motivo de las actuaciones médicas de los profesionales demandados -como personas naturales-, durante su permanencia en el establecimiento clínico privado también emplazado como tercero responsable, a raíz de un parto que se presentaba normal.

El actor promovía principalmente la responsabilidad civil por incumplimiento contractual, derivada de las prestaciones médicas y hospitalarias supuestamente involucradas, solicitando condenar a "los demandados, solidaria, conjunta, individual o subsidiariamente, a restituir lo que se haya dado o pagado con ocasión de este contrato y a pagar una indemnización de perjuicios, de conformidad a las partidas antes estimadas, o la suma que US. considere ajustada a derecho, más intereses, reajustes y costas" (la cita ha sido intervenida gramaticalmente). En el primer otrosí del mismo libelo, dedujo subsidiariamente demanda de indemnización de perjuicios por cuasidelito civil, con fundamento en los mismos elementos fácticos, pidiendo similar condena, pero esta vez "solidariamente".

Por su parte, la jueza de la instancia intentó despejar el planteamiento principal de la demanda, en su lacónico considerando $24^{\circ}$, en el cual llegó atinadamente a la conclusión de que en este caso la responsabilidad contractual no se encontraba comprobada, por falta de invocación y acreditación de sus elementos constitutivos, lo cual resulta palmario en el juicio. Así, ya en la demanda se dejaba ver una cierta confusión del

* Magíster en Derecho, Universidad Austral de Chile. Profesor de Investigación Jurídica en la Escuela de Derecho de la Universidad Austral de Chile. Juez de Garantía. Correo electrónico juanvio@gmail.com. 
propio actor al respecto, puesto que aparte de señalar la existencia de sendos contratos de prestaciones médicas con el profesional tratante (Sr. Venegas) y la Clínica Reñaca, y hacer un enunciado general de sus convenciones principales, no se describen allí con la precisión necesaria, las prestaciones y contraprestaciones esenciales, sus circunstancias y modalidades, la forma exacta en que se produjo el incumplimiento denunciado, como tampoco la vinculación del otro médico demandado (Sr. Ríos) con el mismo. Tales omisiones tienen influencia luego en la prueba que casi completamente apunta a la responsabilidad aquiliana, resultando desprovista de demostración plena la antedicha primera postura del demandante.

$2^{\circ}$ ) Que tampoco le falta razón a la jueza de primera instancia, cuando reconoce en cambio la existencia de la responsabilidad extracontractual por parte de los médicos demandados y de la Clínica de salud aludida como tercero, en los términos recogidos en sus considerandos $25^{\circ}$ y siguientes.

\section{$[\ldots]$}

$\left.4^{\circ}\right)$ Que puede ser que las conductas -omisiones más bien- de los demandados no alcancen la culpa penal de la cual han sido sobreseídos -solo temporalmente- de acuerdo al expediente criminal traído a la vista; pero de ningún modo les excusa de la culpa civil en que han incurrido, de acuerdo a lo dispuesto en el artículo 2314 del Código Civil y según se describe acertadamente en la sentencia del grado.

$5^{\circ}$ ) Que la responsabilidad como tercero de la Clínica Reñaca queda establecida tanto por ser la empleadora directa del demandado Sr. Ríos, en los términos que prevén los artículos 2320 y 2322 del Código Civil, cuanto por ser dueña del lugar en que se verificó el perjuicio y haberle correspondido, en consecuencia, la debida atención del paciente, lo que implica poner a su disposición todos los recursos humanos y técnicos, para la superación de su estado de salud y evitar cualquier complicación. La clínica -y el hospital- no es un establecimiento hotelero, que el paciente o su médico de confianza escoja teniendo en cuenta sólo la calidad de su infraestructura. El paciente confía en que esa clínica pondrá todos los medios ofrecidos a su disposición, para superar el trance de salud que haya motivado su internación.

En efecto, y respecto de la primera responsabilidad de la clínica en relación al hecho de su dependiente sr. Ríos, y tal como ha tenido la oportunidad de decirlo esta Corte en otras sentencias, "la responsabilidad por el hecho ajeno surge, tratándose del hecho de personas capaces, cuando a su responsabilidad la ley agrega la de quien ejerce sobre ella autoridad o cuidado, fundada precisamente en la falta de cuidado ejercido sobre el autor del daño, la que para hacerse efectiva requiere que exista una relación de autoridad, cuidado o dependencia entre el autor del daño y el tercero que resulta responsable" (rol 5-883-2012).

Dicha relación de dependencia existía entre el intensivista Sr. Ríos y la clínica demandada, como ambos no lo desconocen y constituye un hecho establecido de la causa; y esta última no ha probado tampoco haberse encontrado en situación de completa 
ajenidad al acto de su dependiente, en términos de sostener la excepción a dicha responsabilidad (inciso final del referido artículo 2320). De esta suerte, resulta inevitable colegir que dicha clínica está obligada a resarcir solidariamente con su dependiente los daños irrogados con la conducta culposa de él.

Dicha responsabilidad resulta bastante para colegir su obligación de concurrir al resarcimiento de los daños ocasionados por la conducta de su dependiente. Sin embargo, y sólo para cerrar en plena armonía el triángulo jurídico que impulsa la corresponsabilidad de todos los demandados, se puede agregar que la vinculación de la clínica respecto del otro médico, Sr. Venegas, impele en el mismo sentido, ya no por ministerio de los efectos de la dependencia propiamente tal, sino que por el vínculo jurídico creado entre este médico independiente y la clínica; y que obedece a un contrato cuyos resultados no son ajenos para ambos - ni menos para el paciente- y que guarda relación con la forma de organizar y prestar el servicio hospitalario.

El profesor Enrique Paillás explica que "Las clínicas privadas, como todo establecimiento médico, ofrecen un servicio al público en general, el cual acude a ellos confiando en que le darán una atención eficiente" (Responsabilidad Médica, 4ª . Edición, pág. 74 Editorial Conosur, Santiago, año 1999). Para esa "atención eficiente”, el empresario o administrador, debe disponer los medios de organización y control necesarios para que el paciente reciba una atención oportuna, suficiente y de calidad: "Un hospital podría llegar a ser civilmente responsable por el insuficiente, ineficiente o inadecuado sistema de coordinación y control de la labor desplegada por su personal sanitario respecto de una específica atención médica que signifique exponer al paciente a un riesgo mayor que el ordinario" (Responsabilidad civil médica, Marcela Carreño y otros, $1^{a}$ edición, pág.129).

De este modo y acudiendo al sistema de responsabilidad general que regula el artículo 2329 del Código Civil: "Por regla general todo daño que pueda imputarse a malicia o negligencia de otra persona, debe ser reparado por esta", es posible concluir la responsabilidad civil por el hecho propio de parte de la clinica emplazada, que se refiere a la circunstancia de no haber precavido eficientemente un sistema organización y control sobre las actuaciones profesionales de sus médicos externos -en este caso, del Sr. Venegas- y de sus propios colaboradores e instalaciones, en términos que pudiese asegurarse una correcta y segura atención de la paciente.

$6^{\circ}$ ) Que para la consideración de las sumas indemnizatorias que se ordenarán pagar, esta Corte tendrá presente el Baremo publicado en el portal digital del Poder Judicial y que representa un acucioso estudio de carácter académico del promedio de cifras que la jurisprudencia ha manejado para casos semejantes, modificado solamente por las circunstancias adyacentes que han sido materia de los hechos asentados en el proceso.

Y visto, además, lo dispuesto en los artículos 186 y 187 del Código de Procedimiento Civil, se CONFIRMA en lo apelado la sentencia de fecha de primero de junio de dos mil doce, escrita desde fs. 929 y siguientes, con declaración de que la indemnización civil que allí se ordena pagar a los demandados, se rebaja a la suma total de $\$ 160.000 .000$ (ciento sesenta millones de pesos), esto es, \$40.000.000 (cuarenta millones de pesos para el cónyuge sobreviviente y una suma igual para cada una de sus hijas).

[se omiten prevenciones referidas al monto de la indemnización] 
Acordada contra el voto de la ministra Sra. Muñoz en lo que respecta a la responsabilidad atribuida a la Clínica Reñaca S.A. por hecho propio, por cuanto, en su concepto, no aparece que hayan quedado establecidas, en la instancia, las deficiencias en la organización de los medios para atender a la paciente.

Regístrese y devuélvase (tres tomos y agregados en custodia).

Redacción del Ministro Sr. Carlos Aránguiz Zúñiga, y de las prevenciones y disidencia, sus autores.

Rol 5817-2013.

Pronunciado por la Cuarta Sala de la Corte Suprema integrada por los Ministros señor Ricardo Blanco H., señora Gloria Ana Chevesich R., señor Carlos Aránguiz Z., señora Andrea Muñoz S y el Abogado Integrante señor Arturo Prado P. No firma la Ministra señora Chevesich y el Abogado Integrante señor Prado, no obstante haber concurrido a la vista y al acuerdo de la causa, por estar en comisión de servicios la primera y por estar ausente el segundo. Santiago, diecinueve de junio de dos mil catorce.

\section{Comentario}

La sentencia en comento es destacable por varios aspectos. Desde luego porque revisados los fallos dictados por la Corte Suprema de los últimos diez años, en materia de responsabilidad civil por el hecho ajeno de prestadores institucionales privados de salud (clínicas), es el único que contiene una sentencia de reemplazo que se preocupa del factor de atribución de responsabilidad.

Como es sabido, tratándose del factor de atribución de responsabilidad civil extracontractual de las clínicas por el hecho ajeno, la doctrina ha entendido que se está frente a un caso responsabilidad del empresario; de guisa que, ex artículo 2320 inciso $4^{\circ}$ del Código Civil, la responsabilidad se atribuye por culpa presunta. Pero también, cierto sector de la doctrina ha señalado que existe una tendencia objetivante en la jurisprudencia $^{1}$, aproximándose el sistema de atribución a un régimen de responsabilidad estricta, donde no cabe la prueba liberatoria de la diligencia por parte de las clínicas. Pues bien, en principio, la presente sentencia pareciera ser una manifestación de dicha tendencia, aunque -como se verá- la Corte Suprema termina optando por un camino distinto.

En el caso, la Corte Suprema establece la responsabilidad de la clínica por dos factores de atribución distintos: primero por responsabilidad civil por el hecho ajeno i.e. culpa presunta, sobre la base de los artículos 2320 y 2322 del Código por ser la empleadora directa del demandando. En segundo lugar, la Corte imputa responsabilidad a la clínica por el hecho de ser dueña del lugar donde se verificó el perjuicio, ya que por esta circunstancia le corresponde la debida atención del paciente, lo que implica poner a su disposición todos los

${ }^{1}$ Por todos, vid. Zelaya, Pedro (2003), "La responsabilidad civil de hospitales y clínicas privadas: hacia una paulatina responsabilidad estricta por riesgo de empresa", en: Cuadernos de extensión jurídica (U. de los Andes) ( $\mathrm{N}^{\circ} 7$, Santiago), pp.173-205; y en sentido más general Corral, Hernán (2003), Lecciones de responsabilidad civil extracontractual (Santiago, Ed. Jurídica de Chile), pp. 241 y ss. 
recursos humanos y técnicos para la superación de su estado de salud y evitar cualquier complicación (considerando $5^{\circ}$ ). Aquí es donde pareciera que la Corte atribuye responsabilidad estricta a la Clínica, toda vez que "la responsabilidad de la empresa se vincula a la titularidad de bienes o de actividades peligrosas que envuelven una potencial capacidad para causar daños estadísticamente inevitables" ${ }^{2}$. Titularidad que envuelve un riesgo cuya contrapartida es la confianza depositada por la víctima, lo que lleva a la Corte a afirmar que:

La clínica [...] no es un establecimiento hotelero, que el paciente o su médico de confianza escoja teniendo en cuenta solo la calidad de su infraestructura. El paciente confía en que esa clínica pondrá todos los medios ofrecidos a su disposición para superar el trance de salud que haya motivado su internación (Considerando $5^{\circ}$, cursivas agregadas).

Pese a esta afirmación inicial de la Corte, no es claro que efectivamente sea una caso de responsabilidad estricta, porque la sentencia agrega dos consideraciones más respecto de la responsabilidad de la clínica. Por una parte, argumenta en un sentido que pareciera acercarse a la culpa organizacional ${ }^{3}$; por otra, termina afirmando una responsabilidad por el hecho propio ex artículo 2329 del Código Civil. En efecto, la Corte hace responsable a la clínica por el actuar del primer médico tratante (ginecólogo) no obstante ser este independiente (a diferencia del médico intensivista), y para ello argumenta que:

[L]a vinculación de la clínica respecto del otro médico, Sr. Venegas [ginecólogo], impele en el mismo sentido [que respecto del médico dependiente, que dio lugar a la responsabilidad ex 2320 y 2322] ya no por ministerio de los efectos de la dependencia propiamente tal, sino que por el vínculo jurídico creado entre este médico independiente y la clínica, y que obedece a un contrato cuyos resultados no son ajenos para ambos - ni menos para el paciente- y que guarda relación con la forma de organizar y prestar el servicio hospitalario (considerando $5^{\circ}$, cursivas agregadas).

\footnotetext{
2 Zelaya, Pedro (1995), La responsabilidad civil del empresario por los daños causados por su dependiente, (Pamplona, Aranzadi), p. 293.

${ }^{3}$ Que se usa en "casos en que el hecho dañoso ha sido causado por uno o más de estos [dependientes], pero supone la 'culpa' de la organización (del principal) en la medida de su deficiente funcionamiento interno”. Contardo, Juan Ignacio (2013), "Indemnización de perjuicios. responsabilidad extracontractual. culpa por omisión. culpa difusa. Corte Suprema, primera Sala (civil), 13 De julio De 2013, rol n 1729-2013”. en: Revista Chilena de Derecho Privado (Comentario de Jurisprudencia) No21, Diciembre., pp. 343-352. p. 351. Casos donde el daño se ha causado "en razón de la deficiente adopción de medidas organizativas requeridas para evitar los riesgos de accidentes”. Barros, Enrique (2010) [2006], Tratado de responsabilidad extracontractual, (Santiago, Ed. Jurídica de Chile), p. 196, correspondiendo a una responsabilidad por el hecho propio, con lo que se diferencia de la hipótesis del artículo 2320 (y 2322).
} 
Sin embargo, en el caso en comento está claro quién es el agente directo del daño (en la culpa organizacional se suele ignorar o al menos no es necesario determinar ${ }^{4}$ ), quedando establecido además que se trata de un profesional independiente ${ }^{5}$.

Finalmente, la Corte afirma que:

es posible concluir la responsabilidad civil por el hecho propio de parte de la clínica emplazada, que se refiere a la circunstancia de no haber precavido eficientemente un sistema de organización y control sobre las actuaciones profesionales de sus médicos externos [...] en términos que pudiese asegurarse una correcta y segura atención de la paciente. (considerando $5^{\circ}$ ).

De esta guisa, la Corte Suprema, admitiendo la ausencia de control de la Clínica respecto de un médico externo (independiente), la hace responsable por esa ausencia de control. Esto es, una responsabilidad por el solo hecho del riesgo creado en la Clínica. Pero, a diferencia de la primera línea argumental, que se aproximaba al reconocimiento de una responsabilidad estricta por el solo hecho de la propiedad del establecimiento, aquí la Corte abandona la responsabilidad por el becho ajeno y prefiere la formulación de un deber general de cuidado por parte de la Clínica respecto de sus pacientes (una “correcta y segura atención” dice la Corte), cuya contravención, en la especie, vulneraría el principio general del alterum non laedere contenido - para el caso- en el artículo 2329 del Código Civil, atribuyéndole finalmente a la Clínica una responsabilidad por el hecho propio 6 .

Pese a los vaivenes argumentales, la sentencia muestra con claridad que, cuando existe vínculo de dependencia entre el tercero causante del daño y la Clínica (como ocurre con el intensivista), se echa mano de la presunción legal del artículo 2320 del Código, lo que niega la tesis objetivante; pero cuando ese vínculo no aparece claro (como ocurre con el ginecólogo tratante), la necesidad de dar una protección a las víctimas, por medio del patrimonio de la Clínica, motiva acudir al establecimiento de un deber general de cuidado cuya contravención genera responsabilidad por el hecho propio ex artículo 2329 (pudiendo haberse fundado también en el artículo 2314).

${ }^{4}$ Zelaya, Pedro. Op.cit., p. 189.

${ }^{5}$ De este modo, tratándose de un profesional independiente, es difícil derivar de su actuar una responsabilidad por parte de la Clínica, aun bajo el expediente de la culpa organizacional, ya que justamente aquella se basa en el reproche al becho propio de la Clínica en tanto unidad jurídica, pero bajo la suposición que tiene control sobre el agente del daño. Lo que no se da en este caso.

${ }^{6}$ Con todo, es admisible tener presente que el médico fue elegido por la propia víctima, lo que pudiese haber servido para-al menos respecto del daño causado por ese médico- eximir de responsabilidad a la clínica. 